\title{
Children and Youth Advocacy in Africa: Context, Approaches and Lessons
} Adebayo $\mathrm{F}^{*}$

Regional Communications Adviser for South and East Africa (Johannesburg), UNFPA East and Southern Africa, 9 Simba Road, PO Box 2980, Sunninghill, 2157, South Africa

*Corresponding author: Adebayo F, Regional Communications Adviser for South and East Africa (Johannesburg), UNFPA East and Southern Africa, 9 Simba Road, PO Box 2980, Sunninghill, 2157, South Africa, Tel: +27 11603 530; E mail: fayoyin@unfpa.org

Rec date: Apr 26, 2017, Acc date: Aug 01, 2017, Pub date: Aug 20, 2017

Copyright: ( 2017 Adebayo F. This is an open-access article distributed under the terms of the Creative Commons Attribution License, which permits unrestricted use, distribution, and reproduction in any medium, provided the original author and source are credited.

\begin{abstract}
In many African countries, children and young people have become critical stakeholders and advocates in achieving the 'child rights agenda'. In addition, the pervasiveness of social media and information technologies has expanded opportunities and platforms for digital activism by young people. Against this backdrop the paper explores the context, content and complexities of children and young people's advocacy in Africa. It describes the diverse advocacy interventions undertaken to promote their rights, including children's parliament, participation in national and international conferences, Voices of Youth, 'speaking to power' through performances and information campaigns for issue positioning. However, most of the approaches are still donor-driven, adult-initiated and patronising. Besides, the complexity of social change and policy influence and the limitations of digital media create considerable challenges in achieving expected advocacy outcomes by children and young people in society. Thus, the paper argues for a re-examination of existing participation and advocacy paradigms and practices in line with the complexities of development programming and Africa's social and political contexts. Strategies for addressing the weaknesses in children and young people's advocacy are outlined.
\end{abstract}

Keywords: Child rights; Youth mobilisation; Policy influence; Digital advocacy; Activism

\section{Introduction}

Advocacy is one of the foremost approaches for engaging children and young people (CYP) in implementing the child rights agenda. From its etymology, advocacy implies 'speaking on behalf of' or 'pleading the cause of others'. For this article, we conceptualise advocacy by children and young people as activities initiated directly by them or facilitated by advocacy groups to influence norms, social practices, regulation, resource allocation, political decisions or policies that affect them. Such activities may fall within the ambit of campaigning, outreaches, policy dialogue, issue positioning, strategic engagement of different partners and pubic mobilisation for social change [1,2]. Thus, its effectiveness depends on a complex set of variables, sometimes beyond the capacity of the advocate.

Within the global human rights discourse, advocacy is pivotal to achieving human rights principles and outcomes. According to frontline child advocacy agencies [3,4], without the strategic deployment of advocacy tactics, it will be difficult to successfully achieve the child rights agenda. In this context, children and young people are considered as advocates and agents of change [5-7]. Although many agencies have initiated programmes to engage them as major advocates, such efforts are constrained by different institutional and programmatic challenges, such as the status of children in society, the hierarchical family, social and political structures and the inherent intricacies of international development programming $[6,8]$.

Specifically, in Africa, the complex human rights context and the perception of children in society create major challenges for effective advocacy roles by children and young people. First, the patriarchal and patronising nature of society still affects the perception and participation of children and their civic engagement roles $[9,10]$. Second, although the continent has experienced phenomenal growth in digital technologies, this has not significantly altered the status of children in society [11]. The digital divide between parents and children often leads to greater parental control of the use of social media [12]. Moreover, major inequities exist in terms of access and utilisation of digital media by different groups of young people.

In light of this, the paper examines the complexities of CYP advocacy in positioning their issues and agenda in society. The overall goal is to describe the salient tactics and tensions in the role of young people as advocates for their rights in Africa. Such an analysis also has implications for the child participation agenda in general. Based on the examination, it is argued that existing participation and advocacy models and methods in Africa need to be re-examined in line with the current social and political context and the dynamics of development programming.

The paper is organised into five main sections of which this introduction is the first. Second, it explores the linkage between participation discourse and CYP advocacy as the theoretical framework. Third, it describes broad advocacy practices of CYP and the deployment of digital media for advocacy by young people. Fourth, the paper examines major complexities of CYP advocacy and fifth, it makes specific recommendations on how to address the challenges identified.

\section{Participation rights as the basis for advocacy by children and young people}

From a conceptual perspective, advocacy by children and young people is predicated on the participation principles enshrined in various human rights instruments. In particular, Articles 12, 13, 15, 31, and 41 of the Convention on the Rights of the Child encapsulate 
various aspects of child participation, including its forms and conditions. Article 12, which deals with the right of every child to be listened to and for their views to be given due weight when decisions concerning them are being taken, is the touchstone right on their participation. Likewise, the African Charter on the Rights and Welfare of Children embodies provisions for child participation in Articles 7, 8 and 9.

However, the Charter in Article 31 provides for the responsibility of children towards the family and society, the State and other legally recognised communities and the international community. The rationale for specifying responsibility for the child may not have been fully understood in human rights community, but as Kamchedzera argues, it can be justified conceptually within the child rights philosophy approbated by the Charter.

In principle, child participation is a complex concept to operationalize. It manifests various typologies of actions ranging from their involvement in reporting mechanisms [13], engagement in developing programmes that affect them [14], involvement in various levels of governance and policy making [15,16], and participation in international conferences [12,17]. According to Save the Children [4], the advocacy role of children may specifically involve engaging them in legal and policy reform, budget monitoring, national strategies and monitoring and reporting on government performance on international commitments.

Participation also results in different programmatic outcomes. Moore, Melchoir and Davis [18] argues that it enables children and young people to contribute to the process of social change and cultural transformation while Checkoway [19] suggests that it strengthens the capacity of young people to deploy their expertise for social good. Others studies highlight different outcomes, such as: how participation enhances their role in social activism and solving social problems $[20,21]$; how participation contributes to personal development and citizenship [6,22,23]; how participation promotes their engagement with social processes [24]; and how participation advances their voice in social development programming $[25,26]$. Such multiplicity of actions and outcome also reflect in their advocacy roles and approaches.

Besides the diverse participation outcomes, several conceptual paradigms have been proposed to frame its implementation. One of the earliest models is the 'Ladder of Participation' popularised by Roger Hart [27]. It highlights concept relating to degree of tokenism or participation in social issues and the role of adults. However, the approach has been criticised as a misnomer in describing how children participate in society [28]. It is also deficient in articulating child participation within the context of African values and ethos.

In summary, the right to participation presents "a radical and profound challenge to traditional attitudes, which assume that children are to be seen and not heard" [17]. It also lays the foundation for their role in advocacy in society. Nonetheless, there is currently no holistic approach to the theory of child participation [29]. Models of participation rooted in African social development contexts are also missing or not well articulated. Such challenges manifest in the advocacy campaigns and programmes undertaken by children and young people.

In the following section, we shall examine three main domains of CYP advocacy in Africa: community advocacy, national advocacy and transnational advocacy. The categorization is based on information and data obtained from frontline child rights agencies such as
UNICEF, Save the Children, Plan International, World Vision, Child Welfare Association and many others. After the review, some challenges and complexities in implementation are elaborated on.

\section{Patterns of CYP advocacy in Africa}

Community advocacy: The geographic community in which children and young people live is one of the first sites for their advocacy role. Different advocacy actions have been undertaken at this level to address specific social practices, down-stream decisions and instruments of governance.

Advocacy through children groups: In many African countries, children and young people have been formed into social groups which promote different aspects of the child rights agenda. In Malawi, children's clubs such as Edzi Toto (Say No to AIDS) organize and implement community campaigns to change social practices that make young people vulnerable to contracting HIV [30]. The group has also campaigned against early child marriage, teen pregnancy, sexual exploitation, lack of access to sexual and reproductive health commodities and other harmful social practices.

In Nigeria, development agencies have supported the establishment of child rights clubs and even thematic clubs like Sanitation Club, Education, Club, and Child Protection Clubs which promote protection and participations rights of the population [31]. One of the tactics used in local advocacy by young people is storytelling, involving real life stories of violations of child rights at community levels. The stories also highlight the role of duty bearers such as development organizations, the private sector and government institutions.

Speaking truth to local power structures: Local platforms have been established for young people to speak to power structures in many communities. In Swaziland, development agencies have facilitated the creation of intergenerational dialogues with local authorities and community gatekeepers to address the challenge of sexual exploitation in the country. Through the use of community theatre performance, songs and poetry, children and young people have spoken up about the problem of sexual violence against girls in families, schools, villages and communities [32]. Digital technology has also been deployed in influencing decisions at the local level. A project supported by Plan International in Cameroun utilised digital mapping in highlighting the problems faced by young people in the country which resulted in increased resource allocation by the local authorities [33].

Engagement of young people on their empowerment and promotion of their rights: Across the continent, platforms for promoting the voices of young people at the community level have been established. In 2005, UNICEF and other partners supported the establishment of the Rural Voices of Youth aimed at promoting the participation of hard-to-reach young people in rural areas. The overall goal was to ensure that their voice is heard on child rights issues. The initiative has been implemented in the following African countries: Liberia, Gambia, Zimbabwe, Malawi, Ghana, Kenya, Togo, Rwanda, Uganda, Swaziland, Botswana, Cameroon, Ethiopia, Malawi, Egypt, Namibia, Nigeria, and Morocco. Through the project, there has been increased access to information on child rights issues by young people, enhanced social debate on child rights agenda and empowerment of youth advocates as active citizens and change agents.

National advocacy: Children and young people undertake national level advocacy activities targeting changes in a variety of areas: social practices, policies, political decisions and even legal reform. A summary is presented below. 


\section{Harnessing the opinions of young people}

One of the main elements of CYP advocacy is the aggregation and integration of their opinions into public discourse. In the area of legal reform for child rights, testimonies of children were incorporated in the child rights legal reform in both South Africa and Nigeria [32]. Children were part of the advocacy task teams that made presentations to various government institutions, including Parliament. In 2005, UNICEF conducted a Youth Opinion Polls in eight countries in East and Southern Africa to determine their views on different children rights issues in order to frame programme response. Findings from the polls were used by different agencies in developing regional and national advocacy strategies for promoting the child rights agenda [32].

More recently, development partners supported the commencement of an initiative called U-Report in Uganda, which allows children and young people to report via mobile platforms on social issues that affect them. Through the process, the voices of young people (called UReporters) have been heard on immunization, child rights violation and disease outbreaks [34]. Due to the popularity of the initiative, many parliamentarians signed onto the database to monitor social development in their constituencies. The initiative has also been extended to at least 15 African countries in West, East and Central Africa. The various mechanisms for measuring the opinions of young people have increased their voice in public debates and enhanced their empowerment, mobilisation, and connectivity. Yet, a major limitation is the episodic nature of such opinion polls and their limited utilisation in social change and policy processes.

Children's parliaments: An important milestone for CYP advocacy in Africa is the institutionalisation of the child parliament mechanism. Children's parliaments currently exist in the following countries: Nigeria, Rwanda, Zambia, Malawi, Burundi, Mozambique, Tanzania, Ghana, Sierra Leone, and Lesotho. In Nigeria, the Children Parliament established under the collaborative effort of UNICEF and the Federal Ministry of Women Affairs, Children and Social Development, has been entrenched in all 36 States of the federation and also in the Federal Capital Territory [32]. The South African children's parliament was set up as part of the implementation mechanism of the Child Rights Act of 2005 and since its inception has made specific recommendations relating to upholding government accountability, establishing the ombudsman, and implementing a number of social policies.

Clearly, the children's parliament mechanism has become a major platform for participation and CYP advocacy in many African countries. But its effectiveness as a tool for policy and social influence is yet to be fully established. In addition, the extent to which the recommendations from the sessions have been implemented by either young people themselves or governmental institutions is uncertain. An assessment by the Inter Parliamentary Union (IPU) and UNICEF describes the current level of implementation as follows: "Too often, children parliaments are one-off, symbolic events with no follow-up and hence little impact on policy or law making" [35].

Thematic advocacy campaigns: CYP have also undertaken thematic advocacy campaigns for specific issues. Under the platform of Education as Vaccine, young people in Nigeria have deployed a multitude of mobilisation tactics ranging from the production of participatory videos, social media campaigns, leveraging informal relationships and youth outreaches to influence the passage of the HIV and AIDS anti-Discrimination Bill [9]. In Ghana, young people working from different organised groups supported advocacy efforts for the ratification of the African Charter and the Africa Youth Policy. They have also been involved in campaigns to advance the rights of young people around sexual and reproductive health, such as condoms promotion, service provision, comprehensive sexuality education, and HIV policy change. However, many of these initiatives are donordriven and episodic.

Commemorative events: A major advocacy mechanism for children and young people on the continent to advance their agenda is the use of symbolic events such as commemorations and observances. Many countries have institutionalised the National Children's Day, which is the epitome of child participation to highlight children's issues. During such events, children undertake various performances - parades, poems, dances, road show, and marches - to highlight issues that affect them [32].

Also across Africa, the Day of the African Child (DAC) commemorated on 16 June is another milestone for CYP advocacy and participation. The day was first commemorated in 1976 after the massacre of South African children during the apartheid period and since then has become an important platform for CYP advocacy and mobilisation [36]. Other events that have been leveraged at national levels include Africa Malaria Day, World Water Day, Global March against Child Labour, Summit against Drug Abuse, International Peace Day, and the World Health Day. Through such observances and events, CYP have been able to advocate for various themes in the child rights agenda. However, evidence of the impact of their participation is tenuous.

Use of mainstream and digital media: Media engagement is pivotal to advocacy, and in various countries children and young people have been involved in the use of mainstream and digital media to enhance their participation and advocacy. In many countries, development agencies support radio and TV programmes to enhance the voices of young people on major issues that affect them. In Burundi, children are being empowered to express their views on the security situation through the media, while in Zambia children have been engaged as junior reporter's to disseminate reports on issues that affect them.

In Angola, the child-to-child radio initiative promotes the voice of young people on social issues and their impact on children, while in Ethiopia school media has been piloted as a viable tool to promote the voice young people. Since the early 1980s, Uganda has employed the Straight Talk initiative as a creative way of communicating issues relating to HIV in the country. Targeted newsletters such as Open Talk, in Namibia, Choose Life in Rwanda and Koor in Somalia have also been supported by development organisations for national advocacy [32].

Social platforms through Facebook, Twitter, Flickr, YouTube, and Instagram have been established to promote their issues. In the West African counties affected by Ebola, SMS platforms were used to circulate information on the signs and symptoms of Ebola with active engagement of young people. On HIV and AIDS, young people aged 15-24 in South Africa through the support of UNAIDS have been involved in leveraging social media and various digital platforms through an initiative tagged "CrowdOutAids" for community mobilisation and political advocacy on AIDS.

Overall, both mainstream and digital media in Africa have been deployed for CYP advocacy and social mobilization for promoting child rights issues. Besides addressing 'information gaps' in social 
development processes, they have been useful in promoting the child rights agenda in the public domain.

Transnational advocacy: Advocacy by children and young people to promote their agenda has become transnational in nature with several initiatives supported by development organizations and regional institutions. They include:

\section{Regional platforms to speak up}

Regional platforms for transnational advocacy are: Africa Youth Parliament, East Africa Youth Parliament and the Mano River Union Youth Parliament. Particularly, the Africa Youth Parliament is a continental network of youth activists from 50 African countries which highlights youth issues in Africa through a strong and effective voice, increased participation of young people in national and international policy decisions and lobbying for policies that create an enabling environment for increased participation of young people in economies, societies and governance [37]. The parliament also leverages social and policy change through the formation of national youth parliaments and participation in regional and international events.

Another pan-African platform is the "Speak Africa" initiative, a multi-media platform aimed at voicing the opinions and desires of children and youth. It was launched in 2006 by UNICEF and UN ECA to design and implement regional campaigns to promote children and youth rights on the continent. In 2006, the network played a leadership role in implementing advocacy activities for the International Year of Youth, advocated for the ratification of the African Charter on the rights and Welfare of Children and also supported the "No Violence against Children and Youth" campaign with the Africa Union [32]. Tactics used by the group in their advocacy include intergenerational discussion, story writing, blogging, thematic footage production and representation.

The major challenge of these platforms is their questionable level of effectiveness and sustainability. An assessment by the United Nations Youth organization concludes as follows: "The work of national youth councils and youth parliaments is often limited to one-off events. Evidence of current and ongoing activities tends to be lacking". Furthermore, many of the regional advocacy platforms become moribund within short periods of their launch due to weak institutional support from the funders and the high level of mobility of youth leaders.

Participation in regional and international conferences and meetings: A major part of advocacy by CYP in Africa is participation in international conferences and events. It is now customary to see children and young people at high profile conferences, conventions, forums, and congresses on different human rights and development themes. Even global forums such as the United Nations Special Assembly Special Sessions, the World Economic Forum and the International AIDS Conference encourage the participation of young people sponsored by different organizations. Their participation in such events has raised their visibility, enabled them to position their issues in outcome documents and enhanced their networking with different partners.

Yet such forms of participation and advocacy activities are fraught with major limitations. Sometimes their participation is limited to preconferences or side events, thus keeping their issues on the fringes of mainstream discussion. Besides, the meaningfulness of such participation is sometimes questionable. For example, representatives of grass roots groups of domestic girls, self-help street workers and apprentices, observed that their participants at the UN General Assembly Special Session on Children felt isolated by the system and could not contribute to any major discussion [38]. This again underscores the need for appropriate level and type of participation by CYP.

Transnational social media use: Digital media have also been employed by young people for transnational advocacy for their rights. Examples include:

Social media to promote maternal health: A group of young people committed to promoting the campaign on accelerated reduction of maternal mortality in Africa established the Youth4CARMMA project in 2012. The campaign has been linked to the AU engagement on maternal mortality reduction on the continent.

Social media campaigns are routinely developed and implemented by young people during commemorative events and observances and during milestone events and conferences (e.g. International Conference on Sexual and Reproductive Health in Africa - Namibia 2014 and Ghana 2016; and the End Child Marriage Campaigns Addis Ababa 2014 and Zambia 2015).

Social media campaign by Africa's young people was part of the MDG review processes and public debate on the post 2015 agenda for the International Conference on Population and Development (ICPD).

\section{Complexities and challenges of CYP advocacy}

From the foregoing, it is clear that significant progress has been made in engaging CYP for advocacy in promoting and positioning their issues and rights in society. Nevertheless, such efforts raise numerous challenges and complexities both for participation rights and for CYP advocacy as examined below.

\section{Multiple outcomes of participation and advocacy: Voice, Visibility or Influence}

For all practical purposes, CYP advocacy continues to grapple with the challenge of multiple end goals: visibility, voice, mobilisation, networking and influence. This is a reflection of the nebulous nature of participation and advocacy. As earlier noted, participation suffers from a lack of universal operationalization. Thus advocacy by children and young people and their participation role manifests different goals and approaches. But while the spectrum of advocacy function may involve informing, educating, sensitization, networking, alliance building, mobilizing, empowering and many others, the ultimate end game is always influence $[1,39]$. The central question is how CYP advocacy can achieve influence amidst the complex process of development and complication of policy paradox.

In implementing the child rights agenda, children and young people may be the least influential. For instance, concerning the engagement of children in the poverty reduction processes, O'Malley [40] identifies four constrains that undermine the role of children as follows: power relations, ability to influence, appropriateness of children's and young people's engagement and the practical implications of their engagement.

In addition, evidence from the field indicates that due to power differential, it is difficult for children to undertake some of the leadership roles suggested for them in social and policy change. Arguably, the complex nature of issue attention, the dynamics of policy change and the intricacies of cultural transformation may imply that 
Page 5 of 6

certain issues are beyond the direct influence of children and young people. While their voice may be important in the process, it is important to get their participation right to avoid the skepticism that they are proxies of development agents.

\section{The question of tokenism and manipulation}

As expected, child rights advocates frown at tokenism and manipulation in child participation. But many of the advocacy efforts tend to suffer from both weaknesses. In practice, participation and advocacy approaches are essentially projects, initiatives or events which are midwifed, sponsored, facilitated, or funded by aid agencies. Without the technical and funding assistance from development organisations, many of the advocacy efforts of CYP will not exist. Such a situation introduces subtle forms of manipulation to the participation dynamics. At worst, it smirks of 'charity mentality or paternalistic approaches' [5].

Although adults are critical to CYP engagement and participation, to a great extent their role tends to end up as a blend of facilitation and manipulation, herewith dubbed 'faci-pulation'. Despite all the rhetoric around the leadership role of children in participation and advocacy, in practice the degree of child-led advocacy is limited. Besides, an unintended consequence of the current arrangement is the emergence of children and youth leaders who end up as proxies or surrogates of development agencies, representing their sponsors at meetings, conferences and seminars.

A number of structural and institutional challenges also confront CYP advocacy. Adults' attitude to CYP still affects their perception and reaction to their advocacy activities. According to Save the Children [4], the lack of understanding by adults of participation coupled with the status of children in society impacts their disposition to child advocacy efforts. In many African traditions, adults perceive children as those with limited agency.

Mabala [9] underscores the negative frames in which young people are viewed and the impact of patriarchal and patronising attitudes of adult decisions makers. This raises questions on whether adults are taking the advocacy efforts of CYP seriously or if they are just putting up with the fancy of development organisations. Hence, addressing entrenched norms and practices requires a holistic mobilisation approach beyond the short-termed and episodic tactics of advocacy efforts.

Digital advocacy: The advent of digital media has created an unprecedented space for digital activism and civic engagement by young people in social development. And across the three domains examined in this article digital media have become a major element of advocacy by young people. Various social media applications have been deployed to advance their issues as stated earlier. Some of the interventions utilise single media platforms such as Twitter or Facebook, while others adopt multi-media platforms. Based on the current trend, digital activism will continue to be a salient element, if not the most important form, of CYP advocacy. However, the question to address is the effectiveness of such approaches and platforms in achieving the ultimate goal of advocacy. Recognizing the limitations of the digital media in social and policy advocacy is also essential to avoid the danger of arrogating 'uber influence' (all-powerful effect) to them.

\section{Conclusion}

The paper sought to examine the promise and patterns of CYP advocacy in promoting the child rights agenda within the peculiar development context of Africa and the complexities they manifest. Our analysis indicates that advocacy approaches by CYP have evolved over time and integrate several dimensions of participation, such as voice, visibility, mobilisation and engagement. CYP advocacy has been deployed to influence diverse duty bearers across the three domains: community, national and transnational. However, it still reflects the current state of participation and tends to be scripted, events-based, tokenistic, adult-led, and donor-driven.

The situation has resulted in an unintended consequence of youth advocates becoming an elite group or 'agents' and 'proxies' of development institutions that support them. Thus, we argue for a rethinking of the current model of participation and CYP advocacy for a more culturally and contextually-relevant approach that integrates the culture of participation and systemic engagement of children and young people in achieving change for the child rights agenda. It should also address the inequities characteristic of the current practices.

\section{Recommendations}

\section{Key recommendations to improve CYP advocacy are proposed as follows}

Greater coherence of CYP advocacy at all levels: Since most CYP advocacy at various levels is disjointed and uncoordinated, a coordinated framework for seamless CYP advocacy on the child rights agenda is recommenced. The mechanism should develop a framework that various organisations and advocacy groups can operate from. Strengthening networks and partnerships for CYP will assist in achieving this goal.

Addressing inequities in CYP participation and advocacy: Significant inequities exist in the current approaches to CYP advocacy. Specific sub-populations that tend to be side-lined are children with disability, children affected by extreme poverty and peri-urban youth. An equity lens in framing the participation and advocacy approaches of young people is proposed.

Long term approach to advocacy: A sustainable and long term approach to CYP is critical for its success and effectiveness. This requires an independent capacity building structure to equip CYP with necessary advocacy and mobilisation skills. Such skills building may be integrated into existing socialisation processes to make advocacy competence more systemic and improve the culture of participation and civic competence of young people. It will also build a more progressive CYP movement for the child rights agenda and mitigate the 'manipulative' tendencies of different agents.

Enhanced digital advocacy: With the digital age, there is tremendous power in the hands of young people. It is critical to harness such digital power through a more strategic engagement that empowers children and young people as powerful digital activists and advocates of their agenda across the socio-ecological spectrum.

\section{Suggestions for Future Areas of Research}

Conceptual studies that focus on the development of models that help to achieve coherence of CYP advocacy efforts across all domains of advocacy processes - community, national and international levels - 
and across agencies deserve more attention. For now, advocacy by children and young is too fragmentary and disjointed to be effective.

Since the perception of influence is critical to advocacy, exploratory studies on the perception of stakeholders on the advocacy competence and capacity of children and young people will help to determine how to frame appropriate levels of advocacy interventions for them.

Comparative analysis of the lessons learnt on CYP advocacy from various political and cultural settings will enhance experience sharing and knowledge management of child rights activists and advocates.

Studies on the creative engagement of young people in using digital technology for massive social and cultural transformation are required. This should also focus on how young people can create and sustain social movements for their issues and address counter movements that take place as a result of the contested social and political environment.

\section{References}

1. Fayoyin A (2013) Advocacy as a Strategy for Social change: A Qualitative Analysis of the Perceptions of UN and Non-UN Development Workers. J Soc Sci 35: 181-193.

2. Obar JA, Zube P and Lampe C (2012) Advocacy 2.0: An Analysis of How Advocacy Groups in the United States Perceive and Use Social. Journal of Information Policy 2: 1-25.

3. UNICEF (2010) UNICEF and Advocacy: Toolkit and Guidance Paper. New York: UNICEF.

4. Save the Children (2012) Advocacy Training Manual on Children's Rights. Nairobi: Save the children.

5. Hodgkin R, Newell P (2002) Implementation Handbook on the Convention on the Rights of the Child. New York: UNICEF, pp: 1-817.

6. Lansdown G (2005) The Evolving Capacities of the Child. Italy: UNICEF, pp: $1-82$.

7. UNICEF (2003) The State of the World's Children. New York: UNICEF, pp: $1-136$.

8. UNICEF (2013) A (Private) Public Space: Examining the Use and Impact of Digital and Social Media among Adolescents in Kenya. Nairobi: UNICEF, pp: 1-90.

9. Akinfaderin-Agarau F, Fashola T (2011) What Business do Youth have Making HIV and AIDS Laws in Nigeria? Young Citizens: Youth and Participatory Governnance in Africa. London: IIED, pp: 85-94.

10. Mabala R (2011) Youth and "The Hood" - Livelihoods and Neighbourhoods. Environment and Urbanization 23: 157-181.

11. Fayoyin A (2011) Promoting Children's Rights through the New Media: The Nigerian Experience. Journal of Communication 2: 57-65.

12. UNICEF (2013) The Children's Agenda Advocacy Toolkit. Dar es Salaam: UNICEF, pp: 1-144.

13. Baro D (2003) A Tool for Change? Reporting to the UN Committee on the Rights of the Child. London: Save the Children, pp: 1-72.

14. Landgren K (2005) The Protective Environment: Development Support for Child Protection. Human Rights Quarterly 27: 215-248.

15. Guerra E (2002) Citizenship Knows No Age: Children's Participation in the Governance and Municipal Budget of Barra Mansa, Brazil. Environment and Urbanization 14: 71-84.

16. Williams E (2004) Children's Participation and Policy Change in South Asia. London: Childhood Poverty Research and Policy Centre, pp: 1-62.
17. Lansdown G (2001) Promoting Children's Participation in Democratic Decision making. Italy: UNICEF

18. Moore S, Melchoir L, Davis J (2008) Me and the 5 'Ps': Negotiating Rights-Based Critical Disabilities Studies and Social Inclusion. The International Journal of Children's Rights 16: 249-262.

19. Checkoway BN, Gutierrez LM (2006) Youth Participation and Community Change. Journal of Community Practice 14: 1-9.

20. Bessant J (2003) Youth participation: a new mode of government. Policy Studies 24: 87-100

21. Kirshner B (2007) Introduction: Youth Activism as a Context for Learning and Development. American Behavioral Scientist 51: 367-379.

22. Wood D, Larson RW, Brown JR (2009) How Adolescents Come to See Themselves as More Responsible Through Participation in Youth Programs. Child Development 80: 295-309.

23. London JK, Zimmerman K, Erbstein N (2003) Youth-Led Research and Evaluation: Tools for Youth, Organizational, and Community Development. New Directions in Evaluation 98: 33-45.

24. Ho E, Clarke A, Dougherty I (2015) Youth-led social change: Topics, engagement types, Futures. 67: 52-62.

25. Christens BD, Dolan T (2011) Interweaving Youth Development, Community Development, and Social change through Youth Organising. Youth and Society 43: 528-548.

26. Powers JL, Tiffany J (2006) Engaging Youth in Participatory Research and Evaluation. J Public Health Management Practice, pp: S79-S87.

27. Hart R (1997) Children's participation: The Theory and Practice of Involving Young Citizens in Community and Environmental Care. New York, London: UNICEF, Earthscan Publications, pp: 1-205.

28. Reddy N, Ratna K (2002) A Journey of Children's Participation. Bangalore, India: The Concerned for working Children, pp: 1-41.

29. Invernizzi A, Milne B (2006) Beyond Article 12: Essential Readings on Children's Participation. Bangkok: Black on White Publications.

30. NAC (2009) Malawi HIV and AIDS Extended National Action Framework 2010-2012. Lilongwe: National AIDS Commission, pp: 1-53.

31. UNICEF (2008) NCP Journey so far. Lagos: UNICEF.

32. UNICEF (2009) Findings on the Sexual Exploitation of Children in Swaziland. Mbabane: UNICEF.

33. Raftree L, Nkie J (2011) Digital mapping: a silver bullet for enhancing youth participation in governance? Young Citizens: Youth and Participatory Governance in Africa. London: IIED, pp: 43-54.

34. Ogundipe S (2014) U-Report: Developing Community health through mobile technology. Vanguard Newspaper, pp. 1-3.

35. IPU (2011) A Handbook on Child Participation in Parliament. Geneva: IPU, pp: 1-74.

36. AU (2014) The African Committee of Experts on the Rights and Welfare of Children: DAC Concept Note. Addis Ababa: AU.

37. AYP (2011) African Youth Parliament. Nairobi: Communication Initiative.

38. African Movement of Working children and Youth (2001) A World Fit for and By Children: Our views as Working Children in Africa, pp: 1-24.

39. Chapman S (2004) Advocacy for public health: a primer. J Epidemiol Community Health 58: 361-365.

40. O’Malley K (2004) Children and Young People Participating in PRSP Processes: Lessons from Save the Children's experiences. London: Save the Children. 